\title{
Preoperative Uterine Artery Embolization in Women Undergoing Uterus-Preserving Myomectomy for Extensive Fibroid Disease: A Retrospective Analysis
}

\author{
Manon Russ ${ }^{\mathrm{a}}$ Katrin Alexandra Hees ${ }^{\mathrm{a}}$ Miriam Kemmer ${ }^{\mathrm{a}}$ Rolf Richter ${ }^{\mathrm{a}}$ \\ Thomas Kröncke $^{b, c}$ Dirk Schnapauff ${ }^{b}$ Uwe Heimann $^{b}$ Matthias David ${ }^{a}$

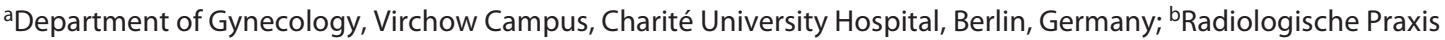 \\ am Kapweg, Berlin, Germany; ' Department of Diagnostic and Interventional Radiology and Neuroradiology, \\ University Hospital of Augsburg, Augsburg, Germany
}

\section{Keywords}

Leiomyoma · Fibroids · Preoperative embolization ·

Myomectomy

\begin{abstract}
Objectives: The aim of this study was to determine if a long versus short interval between preoperative uterine artery embolization (PUAE) and subsequent myomectomy impact perioperative blood loss and the complication rate in cases of enlarged multi-fibroid uterus. Design: In cases of an enlarged multi-fibroid uterus, operative myomectomy can lead to heavy blood loss and consequently increases the risk for transfusion and hysterectomy. PUAE can possibly contribute to a reduction of these risks. Our study was designed to determine if a long versus short interval between PUAE and subsequent surgery impacts perioperative blood loss and complication rate. Participants and Methods: PUAE was performed $24 \mathrm{~h}$ before the planned myoma enucleation in 21 patients between January 2011 and March 2016 (group 1) or 19 days before the operation in 23 patients from March 2016 to May 2018 (group 2). A comparison was made to a historical sample of 57 patients with large myomas $(>10 \mathrm{~cm})$
\end{abstract}

karger@karger.com www.karger.com/goi

Karger $\stackrel{\text { ' }}{=}$

GOPEN ACCESS
(C) 2022 The Author(s)

Published by S. Karger AG, Basel

This article is licensed under the Creative Commons Attribution 4.0 International License (CC BY) (http://www.karger.com/Services/ OpenAccessLicense). Usage, derivative works and distribution are permitted provided that proper credit is given to the author and the original publisher. without PUAE (group 3). Perioperative blood loss, need for postoperative blood transfusion, and postoperative complications were recorded. Subjective improvement of myomarelated symptoms was assessed for each group by a questionnaire. Results: PUAE was carried out successfully without complications in all patients. Conversion to hysterectomy was not needed in any of the PUAE patients but was necessary in one of the control patients. In the three groups' comparison, there was a significant lower risk for high blood loss $(\geq 500 \mathrm{~mL}$ ) in group 1 and a lower but not significant lower risk in group 2 compared to group 3 without an embolization preoperatively. Also, a significant lower risk for postoperative blood transfusion for group 1 (OR 0.02; 0.001-0.328; $p=0.01)$ and 2 (OR $0.02 ; 0.001-0.277 ; p=0.01)$ compared to group 3 was observed. The postoperative complication risk was lower in group 2 (model 1 : OR $0.12 ; 0.016-0.848 ; p=0.03$; model 2 OR $0.07 ; 0.009-0.588 ; p=0.01$ ) compared to group 3. In the context of the postoperative questionnaire, 10 of 11 patients in group 1, 12 of 12 patients in group 2, and 31 of 36 patients from the control group reported an improvement

Manon Russ and Katrin Alexandra Hees share first authorship.
Correspondence to:

Katrin Alexandra Hees, katrin-alexandra.hees@ charite.de 
of their complaints. Conclusion: PUAE is beneficial for uterus-preserving removal of myomas from patients with a substantially enlarged uterus. There is a significant reduction of high blood loss ( $\geq 500 \mathrm{~mL}$ ), need for postoperative blood transfusion, and postoperative complications in patients with extensive fibroid disease after PUAE compared to no intervention before myoma enucleation.

\section{(C) 2022 The Author(s)}

Published by S. Karger AG, Basel

\section{Introduction}

Uterine fibroids are the most common benign solid pelvic tumors in women. In addition to physical complaints (such as hypermenorrhea, dysmenorrhea, and menorrhagia), myomas represent a source of psychological stress for many women [1]. The treatment of symptomatic myomas is pharmacological, through focused ultrasound, by embolization of uterine vessels or by surgical operation [2].

Among uterus-preserving therapeutic options, operative myoma resection (enucleation) is the most widely performed intervention. Yet, for patients with myomas that are large, numerous, or unfavorably located, operative myoma enucleation is associated with an elevated risk for bleeding and hysterectomy [3]. This is especially important to consider for women who wish to keep their uterus for personal or fertility-maintaining reasons. Enucleation of a leiomyoma in an enlarged polyfibroid uterus is challenging for the surgeon too, not least of all because in this case, there is often only a limited possibility for laparoscopic removal [3].

Spraying the myoma with vasoconstrictive substances or temporarily compressing the A. uterina is an intraoperative variation to keep blood loss low during removal of myomas [4]. A third established method is preoperative uterine artery embolization (PUAE). In recent years, it has been reported that PUAE enables enucleation of large myomas with only minimal blood loss [5]. For this, UAE is carried out by an interventional radiologist hours to days before the planned myoma enucleation, thereby devascularizing the leiomyoma and allowing for bloodless dissection $[6,7]$. This combination of two established procedures is intended to preserve the uterus in women with large and multiple fibroids who are at risk for blood loss including subsequent transfusions as well as conversion to hysterectomy.

Besides a few case reports [8-10], several small case series (sample sizes of 5-33) have been published from 2000 to 2018 [5-8, 11-21]. It remains unclear though what the optimal interval is between PUAE and the operation and whether the advantages of a PUAE reported by surgeons can be objectively demonstrated in a comparison against a sample of women without PUAE.

\section{Materials and Methods}

\section{Subjects}

After detailed consultation about the benefits and risks, premenopausal patients of a university myoma referral unit were offered the option of a combined treatment of PUAE and operation, if the following criteria were fulfilled: (1) explicit wish to preserve the uterus, independent of a (current) desire to achieve pregnancy and also either (2A) at least one myoma with a largest diameter $>10$ $\mathrm{cm}$ (according to ultrasound) or (2B) a uterus that was substantially enlarged by several myomas (according to palpation at the level of the navel). Exclusion criteria were as follows: overt renal failure, overt hyperthyroidism, pregnancy, and noncorrectable hypercoagulability.

Between January 2011 and March 2016, 21 patients elected for this combined procedure. The myomas were measured during consultation before any therapy was applied. There was no measurement of the myomas after embolization.

PUAE was performed at a median of $24 \mathrm{~h}$ before the planned myoma enucleation (group 1). From March 2016 onward, the process had to be changed for administrative/organizational reasons. For the patients thereafter, who between March 2016 and May 2018 fulfilled the inclusion criteria $(n=23)$, there was a time interval of 2-3 weeks between PUAE and the operation (group 2). If pain occurred, the patients received pain medication according to the standard analgesic plan for UAE of our clinic.

The clinical course after PUAE and surgery including intraoperative blood loss, myoma size, and weight according to the pathology report, preoperative and postoperative laboratory parameters, and postoperative complications according to patient records were recorded for all patients. Possible postoperative complications included wound healing disorders, fever, cystitis, suture dehiscence, postoperative bleeding, anemia, transfusion, or relaparotomy. The classification of the complications was based on the Clavien-Dindo classification of surgical complications [22]. This classification of surgical complications categorizes the postoperative complications and makes them comparable with other centers. Additionally, a short questionnaire for the evaluation of the late postoperative status was sent postoperatively.

These data were also available for the patients of a comparison sample (group 3$)(n=57)$. They were patients with a dominant myoma $>10 \mathrm{~cm}$ according to the pathology report, who underwent myoma enucleation between July 2003 and December 2009 without PUAE.

This retrospective study was approved by our institutional review board. General written informed consent was obtained from all patients preinterventionally and additionally from all patients who were evaluated by questionnaire postoperatively.

\section{Treatment Protocol}

PUAE was carried out by two experienced interventional radiologists (T.K. and D.S.) under local anesthesia; the open-abdominal myoma enucleation for all patients was carried out by an expe- 
Table 1. Information on the patients, the myoma findings, and the myoma operation, as well as results of the pairwise comparison of some parameters between the three study groups

\begin{tabular}{|c|c|c|c|c|c|c|c|}
\hline Variable & $\begin{array}{l}\text { Group } 1 \\
(n=21)\end{array}$ & $\begin{array}{l}\text { Group } 2 \\
(n=23)\end{array}$ & $\begin{array}{l}\text { Group } 3 \\
(n=57)\end{array}$ & $p_{\text {overall }}$ & \multicolumn{3}{|c|}{ Pairwise comparison $p$ values } \\
\hline Age, years & $43(37.5-47.5)$ & $36(30-39)$ & $37(33-42)$ & 0.005 & 0.002 & 0.006 & 0.396 \\
\hline $\mathrm{BMI}, \mathrm{kg} / \mathrm{m}^{2}$ & $24.2(21.7-28.4)$ & $22.7(20.0-28.5)$ & $23(20.9-25.8)$ & 0.353 & - & - & - \\
\hline Size of the dominant myoma, $\mathrm{cm}$ & $12.7(11.0-14.2)$ & $11.5(9.3-13.0)$ & $12.0(10.7-13.0)$ & 0.295 & - & - & - \\
\hline $\mathrm{EBL}, \mathrm{mL}$ & $475(225-687.5)$ & $350(200-500)$ & $425(250-687.5)$ & 0.679 & - & - & - \\
\hline \multicolumn{8}{|l|}{$\mathrm{Hb}, \mathrm{g} / \mathrm{dL}$} \\
\hline Preoperatively & $12.9(11.7-13.2)$ & $12.4(11.0-13.5)$ & $12.7(11.7-13.8)$ & 0.482 & - & - & - \\
\hline Postoperatively* & $9.5(9.2-10.7)$ & $9.4(8.5-10.8)$ & $9.8(7.9-11.0)$ & 0.818 & - & - & - \\
\hline Change of $\mathrm{Hb}$ value & - & - & - & 0.400 & - & - & - \\
\hline
\end{tabular}

Bold values are significant. EBL, estimated blood loss intraoperatively; BMI, body mass index. * Measured between the 1st and 3rd day postoperatively.

rienced surgeon (M.D.). Myomectomy was carried out as an intracapsular myomectomy with preservation of the pseudocapsule. For most patients undergoing PUAE, a unilateral femoral access was chosen, and both uterine arteries were probed under fluoroscopy using coaxially placed microcatheters. For the flow-directed bilateral embolization of the myomas, particles were used as the embolic agent. Microspheres $500-700 \mu \mathrm{m}$ or $700-900 \mu \mathrm{m}$ in diameter (Embosphere ${ }^{\circledR}$; Merit Medical/Biosphere, Roissy, France) or 500-710 $\mu \mathrm{m}$ nonspherical particles (Contour ${ }^{\circledR}$; Boston Scientific, Natick, MA, USA) were used. In a few cases, at the explicit request of the patient, manually cut gelatin sponge particles (Gelastypt ${ }^{\circledR}$; Sanofi, Frankfurt, Germany) were used as a resorbable embolic agent. The standard analgesic plan for UAE of our clinic was applied to the patients during and after the procedure according to their pain level. The radiation exposure arising during the procedure was documented by means of DoseWatch (GE Health Care; Chalfont St. Giles, UK). The effective dose was calculated by means of XL Dose, version 2.12 (Stamm et al. Hannover, Germany).

\section{Outcome Measures}

Based on Sanders et al. [23], we defined the primary outcome parameters as the blood loss caused by the operation on the basis of three outcome parameters: (1) estimated intraoperative blood loss (EBL), (2) intraoperative and postoperative rate of transfusion, and (3) preoperative/postoperative change of hemoglobin. The secondary outcome parameters were (1) short-term outcomes: the operating time, the occurrence of intraoperative and postoperative complications, the frequency of postoperative bleeding, and unplanned hysterectomies and (2) long-term outcomes: the duration of the official sickness excuse note, the postoperative restriction of daily life, the satisfaction with the surgical scar, and the improvement of complaints.

\section{Statistical Analysis}

IBM SPSS was used for the statistical evaluation. Continuous variables are reported as the median and 25 th and 75 th percentiles. Categorical variables are reported as absolute numbers or percent- ages. The change of hemoglobin value was calculated as the difference of the preoperative and postoperative value. The $\chi^{2}$ test was used to compare categorical variables, and the Kruskal-Wallis test was used to compare continuous variables. Cutoffs for potential risk factors of high blood loss, complications, or erythrocyte concentrates (ECs) transfusion were obtained by receiver operating characteristics analyses. Multivariate stepwise logistic regression analysis with $p_{\text {in }}=0.05$ and $p_{\text {out }}=0.10$ was used to adjust the effects of PUAE for potential confounders.

\section{Results}

\section{Patient Sample and Intraoperative Complications}

The study patients were premenopausal women between 37 and 47 years old, having a body mass index between 21 and 28 (Table 1). Further essential information about patient characteristics and the corresponding myoma findings can be found in Table 1. The localization of the removed myomas was mainly intramural. Some leiomyoma additionally showed a prominent intracavitary part.

The PUAE was carried out without complication in all 44 patients of group 1 and 2 . In group 1 , the calculated median whole-body dose was $3.49 \mathrm{mSv}$, and the median uterus dose was $6.02 \mathrm{mSv}$. In group 2, the calculated median whole-body dose was $2.20 \mathrm{mSv}$, and the median uterus dose was $3.76 \mathrm{mSv}$. The PUAE took place at a median of $24 \mathrm{~h}$ before the planned myoma enucleation in group 1 and 19 days before the operation in group 2 .

Preservation of the uterus was possible for all 44 myoma patients of both of the PUAE groups. One patient in group 1 had a hysterectomy, 14 days postoperatively, in
40

Gynecol Obstet Invest 2022;87:38-45 DOI: $10.1159 / 000521914$
Russ/Hees/Kemmer/Richter/Kröncke/ Schnapauff/Heimann/David 
Table 2. Blood loss $\geq 500 \mathrm{~mL}$, multivariate analysis

\begin{tabular}{|c|c|c|c|}
\hline \multicolumn{4}{|l|}{ Embolization group } \\
\hline Group 1 (surgery within 24 h) & $1.12 ; 0.31-4.074 ; p=0.87$ & $0.04 ; 0.003-0.625 ; p=0.02$ & $0.005 ; 0.000-0.220 ; p=0.01$ \\
\hline Group 2 (surgery after 19 days) & $0.72 ; 0.163-3.189 ; p=0.67$ & $0.1 ; 0.003-1.314 ; p=0.08$ & $0.01 ; 0.000-0.351 ; p=0.01$ \\
\hline
\end{tabular}

Model 1 adjusted for age $\geq 45$ years, total weight $>1,200 \mathrm{~g}$, myomas removed $\geq 20$, or conglomerate formation. Model 2 adjusted additionally for duration of surgery $>70 \mathrm{~m}$.

Table 3. Blood transfusion postoperatively, multivariate analysis

\begin{tabular}{lll}
\hline Predictor & $\begin{array}{l}\text { Univariate } \\
\text { OR; } 95 \% \mathrm{Cl} ; \text { sig. }(p \text { value) }\end{array}$ & $\begin{array}{l}\text { Multivariate model } 1 \\
\text { OR; } 95 \% \mathrm{Cl} ; \text { sig. }(p \text { value) }\end{array}$ \\
\hline Embolization group & & $0.02 ; 0.001-0.328 ; p=0.01$ \\
$\quad$ Group 1 (surgery within $24 \mathrm{~h}$ ) & $0.27 ; 0.032-2.246 ; p=0.22$ & $0.02 ; 0.001-0.277 ; p=0.01$ \\
$\quad$ Group 2 (surgery after 19 days) & $0.24 ; 0.029-2.033 ; p=0.19$ & \\
\hline
\end{tabular}

Model 1 adjusted for myomas removed $\geq 10$.

another hospital, due to uncontrollable vaginal bleeding. In the control group, 1 of 57 patients had an intraoperative hysterectomy. The preoperatively given diagnosis of a benign leiomyoma was confirmed histologically for all patients of all three groups.

\section{Primary Outcome of "Blood Loss"}

Intraoperative blood loss was not significantly different in the three groups (Table 1). Using multivariate analysis and adjusting for risk factors like age $\geq 45$ years, total weight $>1,200 \mathrm{~g}, \geq 20$ myomas removed, or conglomerate formation, there is a significant lower risk for high blood loss $(\geq 500 \mathrm{~mL})$ in group 1 and a lower but not significant risk in group 2 compared to group 3 without an embolization preoperatively (Table 2). When adjusting additionally for surgery duration $>70 \mathrm{~min}$, both embolization groups, 1 and 2, show a significant lower risk for high blood loss.

Intraoperative administration of EC was not necessary in any case for all myoma enucleations after PUAE, but EC was administered in 1 patient in the control group. Postoperatively, 1 patient in each group 1 (4.5\%) and $2(4.4 \%)$ received two ECs. In group 3, 9 patients $(15.8 \%)$ received postoperative transfusions $(p=0.107)$. Table 3 shows a significant lower risk for the need of postoperative blood transfusion for group 1 (OR 0.02; $0.001-0.328 ; p=0.01)$ and 2 (OR 0.02; 0.001-0.277; $p=$

PUAE before Myomectomy for Extensive Fibroid Disease
Table 4. Compilation of complications during the primary inpatient hospitalization

\begin{tabular}{llll}
\hline $\begin{array}{l}\text { Postoperative complications } \\
\text { (Clavien-Dindo grade) }\end{array}$ & $\begin{array}{l}\text { Group 1 } \\
(n=21)\end{array}$ & $\begin{array}{l}\text { Group 2 } \\
(n=23)\end{array}$ & $\begin{array}{l}\text { Group 3 } \\
(n=57)\end{array}$ \\
\hline Grade I & 2 & 0 & 3 \\
Grade II & 3 & 2 & 7 \\
Grade III a b & 0 & 0 & 0 \\
Grade IV & 1 & 0 & 2 \\
Grade V & 0 & 0 & 0 \\
\hline
\end{tabular}

0.01) compared to group 3, when adjusted for myomas removed $>10$.

The results of pairwise comparisons of essential parameters between the groups 1,2, and 3 are displayed in Table 1 . There was no statistically significant difference for the EBL and the $\mathrm{Hb}$ value difference. The operating time was significantly shorter in the control group than in the PUAE groups (Table 1).

\section{Short-Term Outcomes}

Postoperative complications occurred in 6 patients $(28.6 \%)$ in group 1,2 patients $(8.7 \%)$ in group 2 , and 12 
Table 5. Complications, multivariate analysis

\begin{tabular}{|c|c|c|c|}
\hline Predictor & $\begin{array}{l}\text { Univariate } \\
\text { OR; } 95 \% \mathrm{Cl} \text {; sig. ( } p \text { value) }\end{array}$ & $\begin{array}{l}\text { Multivariate model } 1 \\
\text { OR; } 95 \% \mathrm{Cl} \text {; sig. ( } p \text { value) }\end{array}$ & $\begin{array}{l}\text { Multivariate model } 2 \\
\text { OR; } 95 \% \text { Cl; sig. ( } p \text { value) }\end{array}$ \\
\hline \multicolumn{4}{|l|}{ Embolization group } \\
\hline Group 2 (surgery after 19 days) & $0.48 ; 0.097-2.400 ; p=0.37$ & $0.12 ; 0.016-0.848 ; p=0.03$ & $0.07 ; 0.009-0.588 ; p=0.01$ \\
\hline
\end{tabular}

Table 6. Results of the patient questionnaire on late postoperative outcomes

\begin{tabular}{llll}
\hline Parameter & $\begin{array}{l}\text { Group 1 } \\
(n=11 / 21)\end{array}$ & $\begin{array}{l}\text { Group 2 } \\
(n=12 / 23)\end{array}$ & $\begin{array}{l}\text { Group 3 } \\
(n=36 / 57)\end{array}$ \\
\hline Duration of official sick leave, days & $30.5(24-46.5)$ & $30(14.8-39)$ & $28(14-42)$ \\
Postoperative impairment of daily life, ${ }^{*}$ days & $42(20.8-98.0)$ & $28(28-42)$ & $28(14-56)$ \\
Patient-measured scar length, cm & $12(10-15)$ & $13(11-15)$ & $10(9.5-12)$ \\
Would recommend the procedure to a friend, $n$ & $9 / 11$ & $10 / 12$ & $28 / 36$ \\
& $1 \times$ not sure & $1 \times$ not sure & $6 \times$ not sure \\
Satisfied with the surgical scar, $n$ & $10 / 11$ & $11 / 12$ & $\mathbf{0 . 0 4 5}$ \\
Improvement of complaints & $10 / 11$ & $12 / 12$ & $31 / 36$ \\
Late postoperative complications, $n$ & $1 / 11$ & $1 / 12$ & 0.80 \\
\hline
\end{tabular}

* Median and 25th-75th percentile.

patients $(21.1 \%)$ in group 3 (Table 4 ). There was no statistically significant difference between the three groups ( $p=0.727)$. However, when controlling for risk factors like $>7$ myomas removed and even more for surgery duration $>70 \mathrm{~min}$, there is a significant lower risk for postoperative complications in group 2 (model 1 : OR 0.12; 0.016-0.848; $p=0.03$; model 2: OR 0.07; 0.009-0.588; $p=$ 0.01 ) compared to group 3 (Table 5). The multivariate analysis was adjusted in model 1 for $>7$ myomas removed and model 2 additionally for diameter $>11 \mathrm{~cm}$ and duration of surgery $>70 \mathrm{~min}$ (see Table 5 ).

\section{Long-Term Outcomes}

The median interval between the operation and the follow-up survey of the patients was 28 months. The return rate for the questionnaires sent to the patients was different: $52.3 \%$ in group $1(11 / 21), 52.2 \%$ in group $2(12 / 23)$, and $63.2 \%$ in the control group (36/57). The information reported by the patients is presented in Table 6. Significant differences were found only for the length of the scar. One patient in each group, 1 and 2, reported scarring problems as a complication after discharge. The rate of late postoperative complications reported in the control group was higher (27.8\% vs. $9.1 \%$ in group 1 and $8.3 \%$ in group 2$)$. Three patients of this group reported scarring problems. Two patients in the control group said they had another operation and wound healing problems.

\section{Discussion}

Since it was first described by Ravina et al. [24], embolization has established itself as a safe procedure for the treatment of myomas [25]. In recent years, some research groups have been able to show that patients with large, numerous, or difficult to reach myomas undergoing surgical myoma enucleation benefit from PUAE and that the perioperative course is positively influenced, especially blood loss, rates of transfusion, and rates of complications $[6,7,12]$.

PUAE reduces the blood flow in the uterus and subsequently reduces blood loss when scarring the uterus during myomectomy which is an advantage to a temporary uterine ligation during myomectomy. An additional effect for long-term reduced blood flow is the atrophy of small possible left myomas after UAE.
Russ/Hees/Kemmer/Richter/Kröncke/ Schnapauff/Heimann/David 
In our study, the EBL was significantly different between the groups if controlled for size and number of leiomyomas removed. It has been reported that intraoperative blood loss is lower after PUAE than after myoma enucleation only, which for us was and is a reason to offer this combination. Ngeh et al. [5] reported a significantly lower intraoperative blood loss in 5 patients after embolization $(100 \mathrm{~mL})$ versus 14 patients without embolization (400 mL; $p=0.026)$. In the work of Üstünsöz et al. [15] and Tixier et al. [7], there was also a significantly lower intraoperative blood loss for patients with versus without PUAE, whereas Goldman et al. [13] did not find a statistically significant difference.

Perioperatively, the need for ECs in our study was significantly lower in groups 1 and 2, if more than 10 myomas had to be removed. Ngeh et al. [5] have reported that no patients in their PUAE groups needed EC transfusions, while the administration of ECs took place in 3 of 14 patients without PUAE. None of the patients with PUAE were transfused by McLucas et al. [6] $(n=20)$ nor Üstünsöz et al. [15] $(n=15)$, whereas, this was necessary in $12 \%$ and $13 \%$, respectively, of their control groups. These results have been confirmed by various authors, who likewise did not need any transfusions after PUAE $[11,12,14,18]$.

The change of $\mathrm{Hb}$ value was not significantly different in our three groups. Goldman et al. [13] also reported no significant difference between the preoperative and postoperative $\mathrm{Hb}$ values for patients receiving laparoscopic myoma enucleation without versus with PUAE $(p=0.8)$. Tixier et al. [7] by contrast were able to show in their study that the mean drop of $\mathrm{Hb}$ was significantly lower after UAE than without previous embolization.

The operating time was significantly longer in the PUAE groups than in the control group. Only patients who suffer from extensive fibroid disease are offered and finally undergo PUAE. In consequence, the longer operating time could result from the more extended fibroid disease that groups 1 and 2 suffered from compared to group 3. Myomectomy was carried out as an intracapsular myomectomy with preservation of the pseudocapsule if possible. After PUAE, degeneration of the myomas lead to a hindered myomectomy possibly because of a disrupted pseudocapsule; thus, it can be an additional explanation for the prolonged operating time in groups 1 and 2 compared to group 3. Tixier et al. [7] have likewise reported a longer operating time after PUAE in comparison to the control group, although not significantly $(p=0.08)$. But there are also indications of a shortened or comparable operating time after embolization in comparison to myoma enucleation without PUAE $[5,15]$.

PUAE before Myomectomy for Extensive Fibroid Disease
The median radiation exposure from PUAE had wholebody effective doses of 3.49 and $2.2 \mathrm{mSV}$ and uterus doses of 6.02 and $3.76 \mathrm{mSv}$. Given the natural background radiation dose of $2.1 \mathrm{mSv}$ per year, we believe that the radiation exposure from PUAE is acceptable [26]. Complications during the hospital stay arose above all for patients in group 1 (28.6\%) and the control group (21.1\%) (Table 2). Comparing the groups, we see a significant lower risk for complications for patients with large uterus myomatosus in group 2 compared to group 3 without embolization (OR 0.07; 0.009-0.588; $p=0.01$ ). For Malartic et al. [12], there were neither relevant complications nor fever after PUAE. In the PUAE sample from Butori et al. [11], 4 of 33 patients (12.1\%) had postoperative complications. McLucas et al. [6] and Üstünsöz et al. [15] reported no postoperative complications in their PUAE groups, while there was a complication rate of $25 \%$ or $20 \%$, respectively, in their control groups. Ngeh et al. [5] reported that one of 5 patients had fever after PUAE (20\%), while $57 \%$ from the control group developed fever. The most frequent comorbidity after PUAE is postoperative fever, which nonetheless after UAE is often observed in the context of a socalled postembolization syndrome [27].

The parameters on long-term outcomes showed that patients both after PUAE and also without it reported a clear improvement of complaints after the procedure, whereby the rate after PUAE was a bit higher. A clear improvement of complaints is also described in the literature $[12,17]$.

In the literature, a technically easier intraoperative removal of myomas after PUAE has been described $[11,14$, $28]$. In the present work, the surgeon reports that myoma removal was easier after UAE, even more clearly for patients with UAE 19 days than $24 \mathrm{~h}$ preoperatively. The cause for this could be the hyalinization after PUAE-induced infarction of leiomyoma has already set in after a longer interval between PUAE and the operation as well as the wearing off of the inflammatory reaction after infarction of the myoma.

The intervals between the UAE and the operation are different in the literature and span from a few hours [7, $13]$ over 1 to 2 days $[11,12,14,15]$ to 1 week preoperatively [6], without differences in the results being apparent. Studies that investigate different intervals between UAE and the operation have been absent from the literature so far.

Among the limitations of the present work are the single-center study design, the retrospective collection of data, and the small case series. Survey questionnaire was self-developed and unvalidated. Long-term outcomes are 
based on patient self-report, thus subject to bias and memory problems, and we have a low rate of return of questionnaires.

In conclusion, in the comparison of 2 case series with a historical control group, we see significant advantage after PUAE for patients undergoing myomectomy for large myoma and a high fibroid burden regarding blood loss, risk for EC transfusion and complications. Between the two different PUAE/operation intervals, no statistically significant difference was found. Prospective controlled multicenter studies should be carried out to emphasize the advantages of a PUAE for women with large uterus myomatosus.

\section{Acknowledgments}

We would like to thank Michael Hanna, PhD (Mercury Medical Research \& Writing) for translating the manuscript from German into English and providing feedback on the manuscript.

\section{Statement of Ethics}

This retrospective study was approved by our institutional review board, and the requirement to obtain informed consent was waived. Written informed consent was obtained from all patients who were evaluated by questionnaire postoperatively.

\section{Conflict of Interest Statement}

The authors declare that there is no conflict of interest.

\section{Funding Sources}

This research received no specific grant from any funding agency in the public, commercial, or not-for-profit sectors.

\section{Author Contributions}

Manon Russ - data collection and manuscript. Katrin Alexandra Hees - manuscript. Miriam Kemmer - data collection and manuscript. Rolf Richter - statistics. Thomas Kröncke - implementation of PUAE. Dirk Schnapauff - implementation of PUAE. Uwe Heimann - manuscript. Matthias David - director of studies.

\section{Data Availability Statement}

All data analyzed during this study are included in this article. Further inquiries can be directed to the corresponding author.

\section{References}

1 Stewart EA. Uterine fibroids. Lancet. 2001; 357(9252):293-8

2 Scholz C, Wöckel A, Ebner F, Janni W. Multimodale behandlung des uterus myomatosus. Gynäkologe. 2012;45(10):801-8.

3 Vargas MV, Moawad GN, Sievers C, OpokuAnane J, Marfori CQ, Tyan P, et al. Feasibility, safety, and prediction of complications for minimally invasive myomectomy in women with large and numerous myomata. J Minim Invasive Gynecol. 2017;24:315-22.

4 Conforti A, Mollo A, Alviggi C, Tsimpanakos I, Strina I, Magos A, et al. Techniques to reduce blood loss during open myomectomy: a qualitative review of literature. Eur J Obstet Gynecol Reprod Biol. 2015;192:90-5.

5 Ngeh N, Belli AM, Morgan R, Manyonda I. Pre-myomectomy uterine artery embolisation minimises operative blood loss. BJOG. 2004;111:1139-40.

6 McLucas B, Voorhees WD 3rd. The effectiveness of combined abdominal myomectomy and uterine artery embolization. Int J Gynaecol Obstet. 2015;130:241-3.
7 Tixier H, Grevoul J, Loffroy R, Lauferon J, Guiu B, Mutamba W, et al. Preoperative embolization or ligature of the uterine arteries in preparation for conservative uterine fibroma surgery. Acta Obstet Gynecol Scand. 2010;89: 1310-5.

8 David M, Kröncke T. Preoperative uterine artery embolisation for large uterine fibroids with subsequent uterus preservation: three case histories and review of the literature. Geburtshilfe Frauenheilkd. 2012;72:539-42.

9 Paxton BE, Lee JM, Kim HS. Treatment of intrauterine and large pedunculated subserosal leiomyomata with sequential uterine artery embolization and myomectomy. J Vasc Intery Radiol. 2006;17:1947-50.

10 Nabeshima H, Murakami T, Sato Y, Terada Y, Yaegashi N, Okamura K. Successful pregnancy after myomectomy using preoperative adjuvant uterine artery embolization. Tohoku J Exp Med. 2003;200:145-9.

11 Butori N, Tixier H, Filipuzzi L, Mutamba W, Guiu B, Cercueil JP, et al. Interest of uterine artery embolization with gelatin sponge particles prior to myomectomy for large and/or multiple fibroids. Eur J Radiol. 2011;79:1-6.
12 Malartic C, Morel O, Fargeaudou Y, Le Dref O, Fazel A, Barranger E, et al. Conservative two-step procedure including uterine artery embolization with embosphere and surgical myomectomy for the treatment of multiple fibroids: preliminary experience. Eur J Radiol. 2012;81:1-5.

13 Goldman KN, Hirshfeld-Cytron JE, Pavone ME, Thomas AP, Vogelzang RL, Milad MP. Uterine artery embolization immediately preceding laparoscopic myomectomy. Int J Gynaecol Obstet. 2012;116:105-8.

14 Dumousset E, Chabrot P, Rabischong B, Mazet N, Nasser S, Darcha C, et al. Preoperative uterine artery embolization (PUAE) before uterine fibroid myomectomy. Cardiovasc Intervent Radiol. 2008;31:514-20.

15 Ustunsoz B, Ugurel MS, Bozlar U, Duru NK, Ustunsoz $\mathrm{A}$. Is uterine artery embolization prior to myomectomy for giant fibroids helpful? Diagn Interv Radiol. 2007;13:210-2.

16 Schnapauff D, Russ M, Kröncke T, David M. Analysis of presurgical uterine artery embolization (PUAE) for very large uterus myomatosus; patient's desire to preserve the uterus; case series and literature review. Rofo. 2018; 190:616-22. 
17 Namkung J, Kang SY, Chung YJ, Cho HH, Kim JH, Kim MR, et al. Multidisciplinary approach in large-sized submucosal myoma: hysteroscopic myomectomy after uterine artery embolization. J Minim Invasive Gynecol. 2019;26:643-7.

18 Ghiaroni J, Lopez GE, Coutinho Junior AC, Schanaider A. Uterine artery embolization with spherical PVA-PVAc particles as preparation for surgical resection of myomas. Rev Col Bras Cir. 2013;40:386-91.

19 Khalsa B, Costantino M, Goodwin S. Uterine artery embolization followed by elective myomectomy for the treatment of intracavitary fibroids: preliminary experience. J Vasc Int Radiol. 2017;28:47.

20 Chua GC, Wilsher M, Young MP, Manyonda I, Morgan R, Belli AM. Comparison of particle penetration with non-spherical polyvinyl alcohol versus trisacryl gelatin microspheres in women undergoing premyomectomy uterine artery embolization. Clin Radiol. 2005;60: $116-22$.

21 Kemmer M, Schnapauff D, David M. Präoperative myomembolisation vor offen-abdominaler myomenukleation. Eine Fallserie Frauenarzt. 2018;59:836-41.

22 Dindo D, Demartines N, Clavien PA. Classification of surgical complications: a new proposal with evaluation in a cohort of 6336 patients and results of a survey. Ann Surg. 2004;240:205-13.

23 Sanders AP, Chan WV, Tang J, Murji A. Surgical outcomes after uterine artery occlusion at the time of myomectomy: systematic review and meta-analysis. Fertil Steril. 2019; 111:816-27.e4.

24 Ravina JH, Herbreteau D, Ciraru-Vigneron N, Bouret JM, Houdart E, Aymard A, et al.
Arterial embolisation to treat uterine myomata. Lancet. 1995;346:671-2.

25 Kroncke T, David M. Uterine artery embolization (UAE) for fibroid treatment: results of the 6th radiological gynecological expert meeting. Geburtshilfe Frauenheilkd. 2017;77: 689-92.

26 Bundesamt für Strahlenschutz. Ionisierende Strahlung. Available at: https://www.bfs.de/ $\mathrm{DE} /$ themen/ion/umwelt/natuerlichestrahlenbelastung/natuerliche-strahlenbelastung_node.html Accessed 2020 April 15.

27 Parker WH. Uterine myomas: management. Fertil Steril. 2007;88:255-71.

28 Tixier H, Loffroy R, Filipuzzi L, Grevoul J, Mutamba W, Cercueil J, et al. [Uterine artery embolization with resorbable material prior to myomectomy]. J Radiol. 2008;89: 1925-9. 